\title{
FÓRMULAS COOPERATIVAS Y REDES EN TURISMO. APLICACIÓN Y POTENCIAL EN ANDALUCÍA.
}

\section{COOPERATIVE FORMULAS AND NETWORKS IN TOURISM. APPLICATION AND POTENTIAL IN ANDALUSIA}

\author{
Francisco M. Fernández-Latorre \\ Universidad de Sevilla \\ flatorre@us.es
}

Recibido: marzo, 2012.

Versión final aceptada: abril, 2013.

PALABRAS CLAVE: turismo, red, cooperación, cluster, Andalucía.

KEYWORDS: tourism, networking, cooperation, cluster, Andalusia.

\begin{abstract}
RESUMEN
Las formulas cooperativas y redes tienen relevancia en turismo, al ser éste un fenómeno inherentemente reticular. El trabajo identifica redes y formulas cooperativas en turismo, especialmente las desarrolladas en Andalucía. Primero desde el enfoque de la planificación territorial y turística. A continuación se centra en un análisis de clusters económicos y turismo. Se observa una correlación estadística entre riqueza de clusters y competitividad turística de las comunidades autónomas españolas, medidas por Monitur. Por último se propone un modelo de turismo de clusters y se aplica en Andalucía. Se concibe como un modelo-red, que trata de maximizar las relaciones colaborativas entre el turismo y los clusters presentes en cada destino.
\end{abstract}

\footnotetext{
1 El presente artículo procede de la comunicación científica presentada en las Jornadas de Estudios Regionales: Redes y sus territorios: Incidencia en el desarrollo regional. AGE. Sevilla, Junio de 2012.
}

ISSN: 0212-8594 ISSN-e: 2340-2776. № DOI: http://dx.doi.org/10.12795/rea.2013.i30.05 REA 30 (2013):102-126

http://www.publius.us.es/estudios_andaluces 


\section{ABSTRACT}

The formulas cooperatives and networks have relevance to tourism, as this is a phenomenon inherently reticular. The paper identifies formulas networks and cooperatives in tourism, especially those developed in Andalusia. First, from the perspective of spatial planning and tourism. It then focuses on an analysis of economic and tourism clusters. There is a statistical correlation between wealth and tourism competitiveness clusters of Spanish autonomous communities, Monitur measures. Finally we propose a model of tourism clusters and applied in Andalusia. It is conceived as a model-network, which seeks to maximize collaborative relationships between tourism and clusters present in each destination. 


\section{INTRODUCCIÓN.}

El turismo sostenible debe considerar su incidencia y apoyo mutuo en otros sectores y evitar que una economía dependa en exceso del turismo (PNUMA, 2006). De hecho, la actividad turística implica inherentemente la existencia simultánea de redes origendestino, redes imbricadas en sistemas de ciudades e infraestructuras ligadas, entre nodos -que concentran atractivos y servicios-, dentro y fuera del cluster turístico (Fernández, F.M., 2012). La naturaleza reticular del turismo se autoamplifica y extiende a lo largo de todas sus piezas y su ciclo vital. En la medida que constituya un tejido vivo y dinámico, que integre cooperativamente la acción de los distintos agentes, turistas, planificadores públicos y privados, intermediarios turísticos en destino y origen, transporte, gestores de instalaciones de alojamiento y restauración, centros de conocimiento, servicios turísticos, población local -y otros sectores económicos-, aumentará su eficiencia.

El territorio turístico posee un conjunto de atractivos que actúan como detonantes y causa primera del flujo turístico. Con el tiempo, el sistema turístico evoluciona hacia un incremento de los flujos turísticos, aparecen nuevos destinos competidores, nuevos productos y tendencias, que requieren esfuerzos mayores de creatividad y recursos. La creación y consolidación de redes colaborativas es una respuesta ante estas tensiones competitivas. El «capital territorial» comprende elementos que suelen estar incorporados de manera estable a los lugares ("inmóviles"), no hallarse fácilmente en otro lugar con la misma calidad, y ser difícilmente reproducibles en plazos breves de tiempo. Ejemplos: el banco de conocimientos local, el capital social, la heterogeneidad cultural, la capacidad institucional; los recursos renovables e incrementables, pero que sólo se pueden producir en el medio o largo plazo (Dematteis, G. y Governa, F., 2005). En suma, redes y capital social son parte esencial del capital territorial y turístico.

El fenómeno turístico comprende municipios y territorios "no turísticos", por ejemplo atracciones o escenarios distantes de los núcleos de alojamientos y servicios, -"sin camas turísticas"- fundamentales en su funcionamiento e imagen, con frecuencia, minusvalorados y al margen de sus beneficios. Por ello, la región turística es un concepto intuitivo en un principio, pero nebuloso, polisémico y variable conforme se profundiza en él. La división del espacio en unidades distintas y precisas responde a una necesidad política evidente y antigua (Espejo, C., 2003). Para Lozato-Giotart, (1987) se trata de un "área con cierta densidad de frecuentación turística y con una imagen que la caracteriza". A menudo se confunde o identifica con un conjunto natural en cuyo interior queda englobada. Por ejemplo, constituye una región turística el conjunto de grandes núcleos o focos de importante frecuentación turística del litoral, localizados en diversos municipios, limítrofes y pertenecientes a un mismo conjunto geográfico. La regionalización tiene sentido en función del objetivo asignado. De ahí se deduce la elección de las variables, y por tanto, de las interacciones entre sus

ISSN: 0212-8594 ISSN-e: 2340-2776. № DOI: http://dx.doi.org/10.12795/rea.2013.i30.05

REA 30 (2013):102-126

http://www.publius.us.es/estudios_andaluces 
elementos (Dollfus, O., 1986). En consecuencia, el enfoque de región turística -y de sus redes integrantes- dependerá de la concepción de región que se adopte: región natural, región funcional, región histórica, región cultural, región políticoadministrativa, región sistémica, región geográfica como producto de la acción humana, o región económica, vinculada a una región por un Plan asociado.

La región turística viene modulada por los agentes intermediarios que comercializan los destinos, y contribuyen a conformar el imaginario de la región turística, en conjunción con los planificadores y gestores de los destinos en las distintas escalas. La región turística es especial por ser una región híbrida y cambiante. Hibrida por ser producto combinado de una región económico-funcional, donde la actividad turística está presente, y ser al mismo tiempo región geográfica resultado de la acción humana diferencial pretérita, actual y futura, coincidente o no con divisiones políticoadministrativas. En cualquier caso, con presencia de flujos turísticos cambiantes, e identificable claramente del resto de zonas en la mente de los turistas, de touroperadores, planificadores turísticos, y de la población local. Normalmente, reconocible con una imagen y denominación propia, y vinculada físicamente a un ámbito espacial concreto, incluso a un tipo de experiencia turística particular, dependiente del segmento y cuenca-origen del turista-consumidor, y del producto turístico, todos ellos de naturaleza mutante.

La marca integrada de una red de establecimientos y espacios turísticos hace tangible la reputación de éstos, imprime una expresión territorial unitaria, y aporta valor como "región turística", reconocimiento, protección legal y comercialización. Para que surta efecto, la marca ha de formar parte lógicamente de todo lo que hace, se conoce y se percibe del destino. Es necesario determinar su esencia o "núcleo duro", y fomentar un comportamiento consonante que unifique criterios y actuaciones bajo una estrategia territorial común.

Por tanto, la formación de una red turística implica enlazar funcionalmente elementos territoriales y actores turísticos, inicialmente inconexos, con el fin de alcanzar un objetivo compartido y coherente, como la promoción de un destino, de un producto turístico, o bien de un plan o estrategia turística.

\section{OBJETIVOS.}

Los objetivos centrales del trabajo son i. identificar redes y formulas cooperativas en turismo, especialmente las desarrolladas en Andalucía ii. esbozar un modelo de turismo que tome como base los clusters presentes en la región.

ISSN: 0212-8594 ISSN-e: 2340-2776. № DOI: http://dx.doi.org/10.12795/rea.2013.i30.05

REA 30 (2013):102-126

http://www.publius.us.es/estudios_andaluces 


\section{METODOLOGÍA.}

Una primera aproximación consiste en identificar formulas y redes genéricas, con especial atención a las que tienen un origen relacionado con la planificación territorial y turística, junto a las redes de ciudades turísticas. En segundo lugar se estudia el caso de Andalucía. Para ello se identifican redes y proto-redes en Andalucía desde distintos ámbitos y enfoques. En primer lugar, desde el enfoque de la planificación territorial y turística, desde la experiencia de comarcalización e iniciativas andaluzas de turismo sostenible, y de redes de ciudades turísticas andaluzas. Un segundo bloque se refiere al estudio desde la óptica del cluster. Para ello se analiza la correlación estadística entre riqueza de clusters y competitividad turística, medida por el indicador Monitur. A continuación se realiza un análisis de clusters en Andalucía y posibles relaciones con el turismo, tanto a nivel regional, como en consorcios y mancomunidades turísticas. Por último se propone un modelo de turismo de clusters y se aplica en Andalucía.

\section{RESULTADOS.}

\subsection{FÓRMULAS Y REDES COOPERATIVAS EN TURISMO.}

\subsubsection{PLANIFICACIÓN TERRITORIAL-TURÍSTICA.}

Para contextualizar y comprender la situación actual de las redes turísticas en España, es preciso en primer lugar remontarnos a la Ley 197/1963, de 28 de diciembre, de Zonas y Centros de Interés Turístico Nacional. Esta ley creó el concepto de Zona de Interés Turístico Nacional -ZITN-, entendida como un espacio geográfico amplio y adecuado para su promoción turística, bien dotado, y que dejado a la acción espontánea de la iniciativa privada bien podría frustrarse en su desarrollo.

Desgraciadamente, la Zona de Interés Turístico Nacional nunca fue un concepto técnicamente bien definido, confundiéndose con frecuencia la promoción entendida como publicidad con la verdadera creación de productos y su integración territorial (Galiana, L. y Barrado, D., 2006). Es posible que este deficiente desarrollo teórico de la Zona frente al más simple concepto de Centro de Interés Turístico Nacional (CITN), producto urbano-turístico individualizado con más de 500 plazas y 10 ha de superficie, supusiese la preeminencia de éstos frente a aquéllas. El resultado fue un escaso protagonismo de las Zonas de Interés Turístico Nacional frente a los Centros de Interés Turístico Nacional; no se llegó a aprobar finalmente ninguna, a pesar de que se avanzó notablemente en las de la Costa del Sol y la Costa Brava. Es decir, en esos albores se produjo una nuclearización, bien distinta a una regionalización, que bien pudiera haber tomado una escala comarcal, y mayor capacidad para derivar en proto-redes turísticas colaborativas.

ISSN: 0212-8594 ISSN-e: 2340-2776. № DOI: http://dx.doi.org/10.12795/rea.2013.i30.05

REA 30 (2013):102-126

http://www.publius.us.es/estudios_andaluces 
Un año después de la ley 197/1963, se publicó la Orden de 31 marzo de 1964, por la que se creaba el «Registro de Denominaciones Geoturísticas», originando una especie de denominación de origen turística para uso promocional., en cierto modo, germen de proto-red, no suficientemente organizada ni con actuaciones coordinadas. El nombre de la denominación Geoturística podía ser utilizado para la promoción turística de la zona. Así surgieron denominaciones como la "Costa Cálida» para toda la zona del litoral costero de la Región de Murcia, Costa Dorada, del Azahar y Blanca, Costa de la Luz, Costa Brava, Costa del Sol y las Rías Bajas Gallegas, entre otras.

Figura 1. Centros de Interés Turístico Nacional aprobados en el periodo 1966-1975.

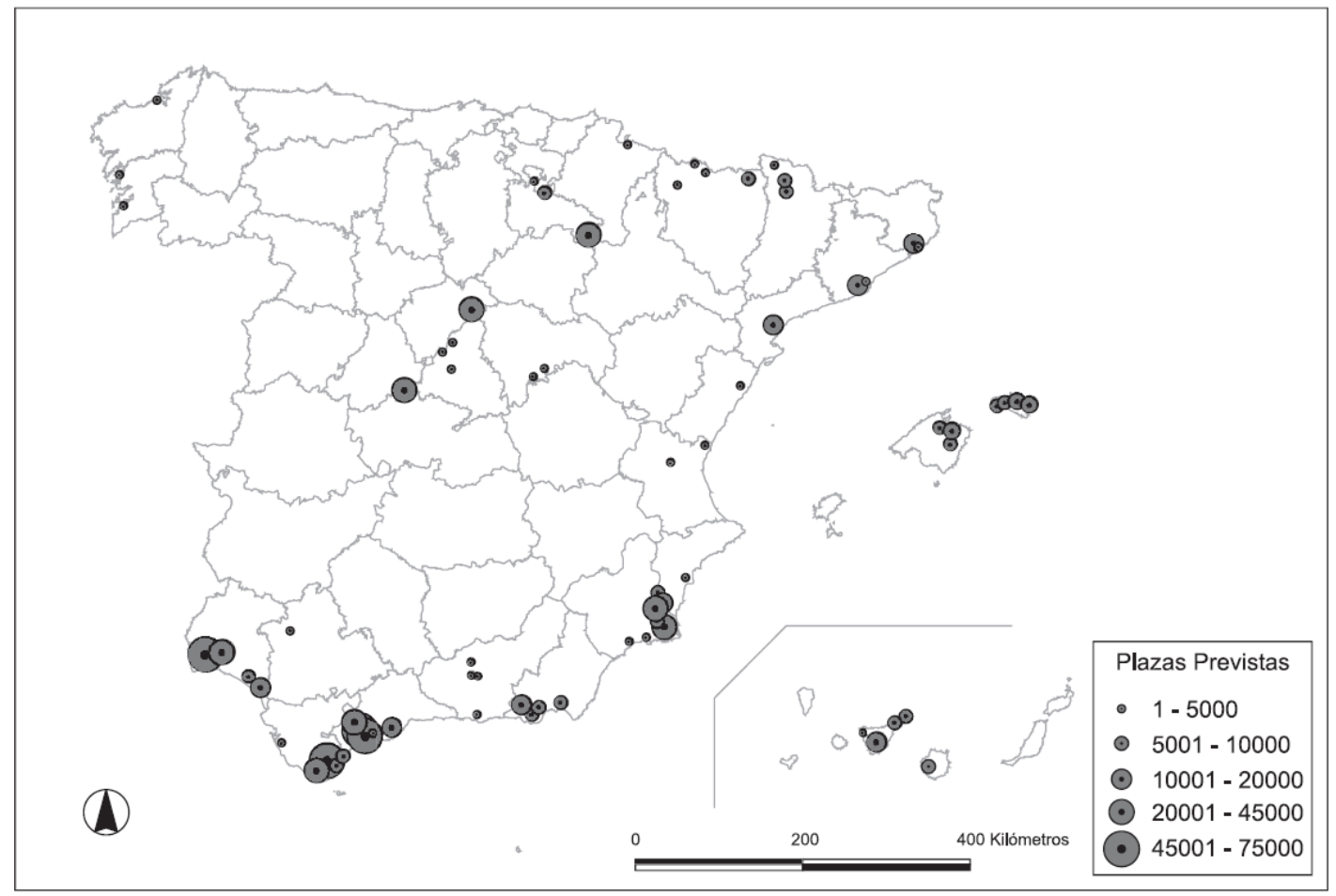

Fuente: Galiana Martín, L. y Barrado Timón, D. (2006).

Las zonas geoturísticas normalmente tienen carácter intraestatal y son áreas turísticas con características más o menos homogéneas con una imagen que las identifica y una funcionalidad homogénea en cuanto a promoción (Vera, F. 1997). La unidad administrativa provincial es empleada con frecuencia como región turística, pese a la artificialidad que conlleva. Por su parte, las Redes de espacios naturales protegidos, especialmente los Parques Nacionales y los Parques Naturales, han jugado un papel importante en la formación de redes de cooperación turística supramunicipales. El paraguas de la denominación de "Parque" aporta un valor de imagen bien valorado por turistas y operadores turísticos. Además, propiciado por la existencia de Planes Turísticos o Programas de Uso Público en estos espacios, dotados de órganos que permiten cierta unidad de gestión, personalidad jurídica propia, así como canales para la participación de los municipios y actores locales.

ISSN: 0212-8594 ISSN-e: 2340-2776. № DOI: http://dx.doi.org/10.12795/rea.2013.i30.05 
El Reglamento 1082/2006 del Parlamento Europeo y del Consejo, de 5 de julio de 2006, por el que se crea la figura de la Agrupación Europea de Cooperación Territorial (AECT) constituye un hito relevante para la cooperación territorial intermunicipal y turística. El Observatorio ESPON (European Spatial Planning Observation Network), defiende que la «integración de las áreas fronterizas puede impulsar la formación de regiones funcionales». Un ejemplo es el denominado "Desarrollo Turístico de la Frontera», centrado en la identificación de recursos patrimoniales de gran valor como oferta cultural y de ocio, adscrito al Programa Operativo Transfronterizo (Manero, F., 2012).

\subsubsection{PLANIFICACIÓN Y FOMENTO SECTORIAL DE LA COOPERACIÓN TURÍSTICA.}

Los Planes de Excelencia y Dinamización Turística (PEDT) son instrumentos de cooperación entre diferentes administraciones y agentes, que implican a la administración estatal, autonómica y local en su gestión, junto a la participación de agentes privados y asociaciones empresariales (Brunet, P., et al, 2005). Tienen por tanto, potencial para implantar planes y proyectos en ámbito supramunicipales, caso de comarcas y mancomunidades.

En un mercado donde la microsegmentación es crucial para ser más competitivos, la creación de clubs de producto es de gran transcendencia. Se tratan de unidades de gestión formadas por agentes públicos y privados involucrados en la prestación de servicios conexos para satisfacer nichos y motivaciones especificas de la demanda turística (Exceltur, 2011). El Monitor de competitividad turística relativa de las comunidades autónomas españolas (Monitur), ofrece una interesante parametrización de los clubes de producto. Según ésta, los clubes de producto incluyen desde el diseño de los atributos y componentes del producto, el establecimiento de criterios selectivos de calidad e imagen para las empresas que formen parte del club y lo presten, la realización de estudios de mercado para el conocimiento de la demanda, el diseño de estrategias de comercialización y marketing para la atracción de clientes, hasta el impulso de programas formativos de especialización sobre el producto dirigidos a los trabajadores. En el indicador Monitur de 2010, se establecen tres condiciones de partida que todo club de producto debe cumplir para poder ser evaluado:

1. Que responda a una motivación.

2. Que integre diversos subsectores o empresas que conforman la cadena de valor del producto turístico, buscando sinergias asociativas entre los distintos prestadores de servicios.

3. Que se encuentre accesible para el turista a través del portal institucional de turismo de la Comunidad Autónoma.

ISSN: 0212-8594 ISSN-e: 2340-2776. № DOI: http://dx.doi.org/10.12795/rea.2013.i30.05

REA 30 (2013):102-126

http://www.publius.us.es/estudios_andaluces 
Una vez determinado si los Clubes de Producto satisfacen estos tres elementos, Monitur valora un conjunto de parámetros básicos que deben cumplir. El subindicador resultante se calcula como suma del total de criterios, a saber:

1. Dispone de una unidad de gestión diferenciada

2. Dispone de una unidad de gestión con personalidad jurídica propia.

3. Participa el sector privado con aportaciones económicas.

4. Realiza y/o participa en estudios e investigaciones de mercado.

5. Realiza acciones propias de promoción y marketing.

6. Desarrolla programas específicos de formación.

7. Oferta un precio de los servicios que lo integran.

\subsubsection{REDES DE CIUDADES TURÍSTICAS.}

En España las ciudades incluidas en la Lista del Patrimonio de Mundial de la UNESCO constituyen un referente para explicar la derivación de redes turísticas cooperativas a partir de una certificación internacional de reconocido prestigio. Trece de estas ciudades forman el Grupo de Ciudades Patrimonio de la Humanidad de España, asociación sin ánimo de lucro creada en 1993 para trabajar en la resolución conjunta de los problemas de índole diversa (urbanos, sociales, patrimoniales, culturales) que afectan a este tipo de ciudades (García, M., 2007). A partir de este grupo se configura en el año 2004, y ya para el ámbito estrictamente turístico, el Club de Producto Ciudades Patrimonio.

García Hernández señala con precisión el referido proceso evolutivo, que enunciamos a continuación. Algunas de las Ciudades Patrimonio de la Humanidad de España se han dotado de estructuras de gestión turística más potentes que los departamentos municipales. El desarrollo de estas estructuras, (fundaciones, empresas municipales, consorcios), ha sido en algunos casos consecuente o paralelo al desarrollo de Planes de Excelencia o Dinamización Turística y cuentan con organismos autónomos de promoción y/o gestión turística en siete de las trece ciudades del grupo.

Dentro de las redes turisticas patrimoniales, que permiten crear y consolidar sinergias entre destinos y espacios, caben señalar Art Cities in Europe, la Red de Juderías de España o el Camino de Santiago, entre otras. La mayor parte de estas iniciativas se centran en la promoción y comercialización conjunta, orientada a diversificar la oferta mediante la creación de productos que distribuyan mejor los flujos turísticos entre los distintos recursos a lo largo del año (Tresserras, J.J. y Matamala, J.C., 2005).

La Red Cittaslow es una novedosa red turística (http://www.cittaslow.es/filosofia.html) de gran potencial en España, que se distingue por:

ISSN: 0212-8594 ISSN-e: 2340-2776. № DOI: http://dx.doi.org/10.12795/rea.2013.i30.05

REA 30 (2013):102-126

http://www.publius.us.es/estudios_andaluces 
-Favorecer las producciones autóctonas tradicionales de calidad vinculadas al territorio

- Fomento de la hospitalidad y convivencia entre habitantes y turistas.

- La población de las ciudades de la red no puede ser superior a 50.000 habitantes.

- La política urbanística ha de servir para mejorar el territorio, no para ocuparlo.

\subsection{EL CASO DE ANDALUCÍA.}

\subsubsection{LA PLANIFICACIÓN TERRITORIAL Y TURÍSTICA EN ANDALUCÍA.}

El Plan de Ordenación del Territorio de Andalucía (POTA) esboza una serie de redes territoriales, en la doble vertiente del patrimonio, natural y cultural, de cara a su aprovechamiento y referencia para desarrollos ulteriores (figura 2).Estas redes se pueden considerar en los planes territoriales de ámbito subregional, planes sectoriales y urbanísticos, así como en estrategias e instrumentos de carácter voluntario. EI POTA considera particularmente la red de espacios naturales protegidos, la red fluvial principal del Guadalquivir, las zonas húmedas interiores y espacios paisajísticos de interés, junto a una red de asentamientos vinculados estrechamente a estas redes naturales, así como de pasillos potenciales de conexión entre estos diferentes ámbitos. Complementariamente, define una red de referentes patrimoniales de naturaleza histórico-cultural, caso del triangulo Sevilla-Córdoba-Granada, redes de ciudad patrimoniales y redes de centros históricos rurales. Se añaden redes temáticas, como la red de ciudades Carolinas, redes de ciudades y territorios mineros, y redes culturales como la Bético-Romana o la del Legado Andalusí. Vinculado a la red fluvial del Guadalquivir se ha elaborado un Plan de Acción para el Desarrollo Rural Sostenible que incluye a sus principales afluentes (Contreras, G.A. y Jiménez, E., 2010).

Los Planes de Ordenación del Territorio de ámbito subregional incluyen ámbitos y parámetros que orientan los futuros desarrollos supramunicipales, que delimitará el planeamiento urbanístico municipal y supramunicipal (éste último, a través de Planes de Ordenación Intermunicipal, no muy frecuentes, y Planes Especiales plurimunicipales. A falta de un régimen jurídico de comarcas consolidadas, los Planes de ámbito subregional elaborados actúan en cierto forma a modo de "comarcas-plan", si bien cada una lo hace de forma separada. La mayoría de Planes de Ordenación del Territorio de ámbito subregional aprobados, en tramitación o elaboración se corresponden con las grandes aglomeraciones urbanas y espacios turísticos: litorales y urbanos. La red de espacios naturales protegidos de Andalucía juega un importante papel para conformar redes turísticas y marcas asociadas. Destacan la Marca Parque Natural de Andalucía, la Etiqueta Doñana 21 para empresas y productos de la Comarca de Doñana, y la Carta Europea del Turismo Sostenible en Espacios Naturales Protegidos, promovida por la Federación EUROPARC. La Reserva de la Biosfera Transfronteriza entre Andalucía y Marruecos es una experiencia pionera

ISSN: 0212-8594 ISSN-e: 2340-2776. № DOI: http://dx.doi.org/10.12795/rea.2013.i30.05

REA 30 (2013):102-126

http://www.publius.us.es/estudios_andaluces 


\section{Francisco Fernández Latorre}

Fórmulas cooperativas y redes en turismo. Aplicación y potencial en Andalucía.

intercontinental, de gran complejidad por el número y diversidad de espacios naturales y socioeconómicos a gestionar.

Figura 2. Planificación turística en el POTA: redes de referentes patrimoniales.

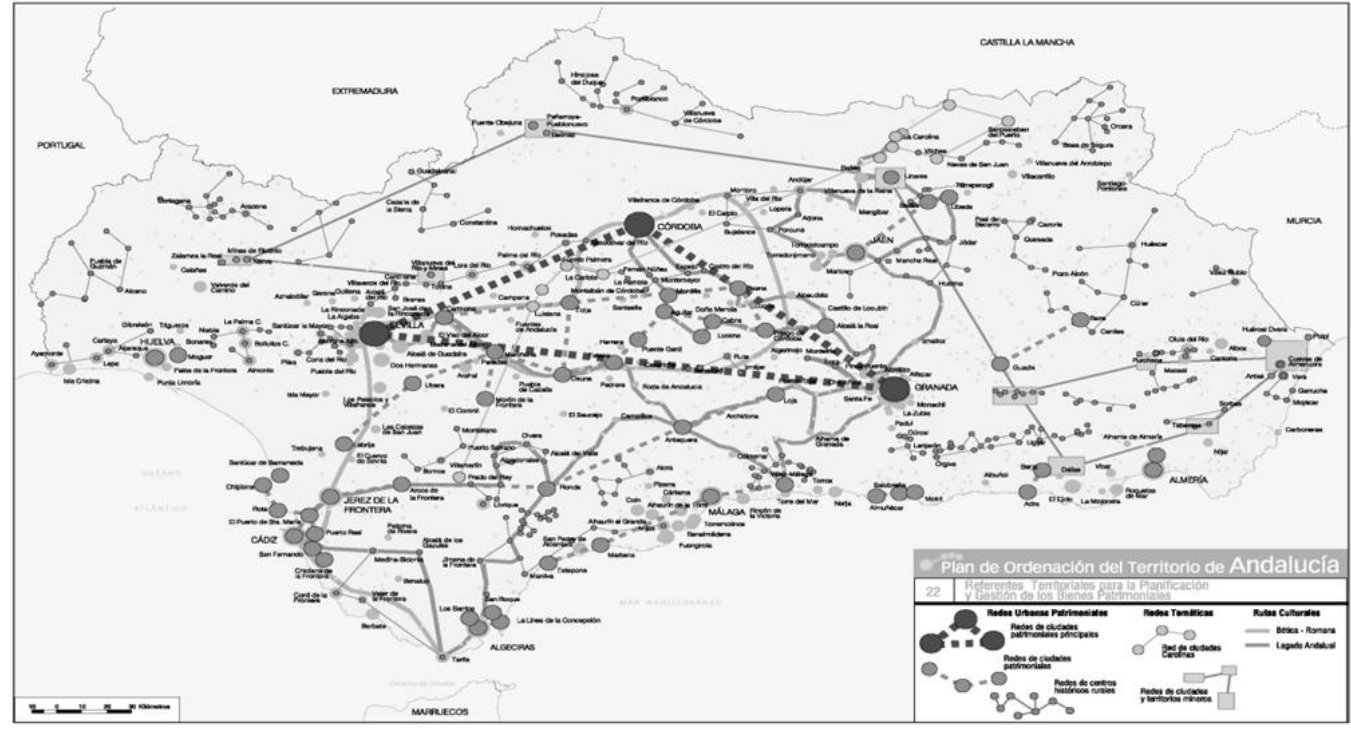

Fuente: Plan de Ordenación del Territorio de Andalucía (2006).

Tabla 1. Determinaciones de los planes de Ordenación del Territorio de ámbito subregional de contenido turístico.

\begin{tabular}{|c|c|c|c|}
\hline Ámbito & $\begin{array}{l}\text { Delimita zonas } \\
\text { turísticas }\end{array}$ & $\begin{array}{l}\text { Edificabilidad } \\
\text { turística }\end{array}$ & Observaciones \\
\hline Aglomeración urbana de Granada & - & - & $\begin{array}{l}\text { Incluida en red principal de } \\
\text { ciudades patrimoniales. }\end{array}$ \\
\hline Poniente Almeriense & - & Sí & Turismo litoral maduro. \\
\hline Sierra de Segura & - & - & $\begin{array}{l}\text { Turismo interior en zona } \\
\text { periférica de Parque } \\
\text { Natural pionero en turismo. }\end{array}$ \\
\hline Ámbito de Doñana & Sí & Sí & $\begin{array}{l}\text { "Hinterland turístico" } \\
\text { vinculado a Doñana. }\end{array}$ \\
\hline Bahía de Cádiz & - & - & Turismo litoral maduro. \\
\hline Litoral Occidental de Huelva & - & Sí & $\begin{array}{llr}\begin{array}{l}\text { Turismo } \\
\text { desarrollo }\end{array} & \text { itoral } & \text { con } \\
\text { reciente. } & & \\
\end{array}$ \\
\hline Costa del Sol Occidental & Sí & Sí & $\begin{array}{lrr}\text { Turismo litoral } & \text { muy } \\
\text { maduro. Primer cluster } & \\
\text { turístico andaluz. } & \\
\end{array}$ \\
\hline Costa del Sol Oriental-Axarquía & Sí & Sí & $\begin{array}{l}\text { Turismo litoral maduro con } \\
\text { desarrollo posterio al de la } \\
\text { Costa del Sol Occidental. }\end{array}$ \\
\hline
\end{tabular}

Fuente: Elaboración propia a partir de Plan General del Turismo Sostenible de Andalucía 2008-2011

ISSN: 0212-8594 ISSN-e: 2340-2776. № DOI: http://dx.doi.org/10.12795/rea.2013.i30.05

REA 30 (2013):102-126

http://www.publius.us.es/estudios_andaluces 


\subsubsection{COMARCALIZACIÓN E INICIATIVAS ANDALUZAS DE TURISMO SOSTENIBLE.}

Las experiencias de comarcalización turística integral de una comunidad autónoma en España son muy escasas. En Andalucía, la Orden de 14 de marzo de 2003 para la planificación turística y deportiva estableció un mapa comarcal turístico-deportivo, que finalmente fue derogado. En la práctica las comarcas turísticas trazadas en este mapa tuvieron escasa aplicación en la planificación y la gestión real del turismo. Además, el tener una naturaleza mixta (turístico-deportiva), complicó aún más su delimitación y funcionamiento efectivo.

Figura 3. Mapa de comarcas de Andalucía para la planificación turística y deportiva (según Orden de 14 de marzo de 2003, derogada).

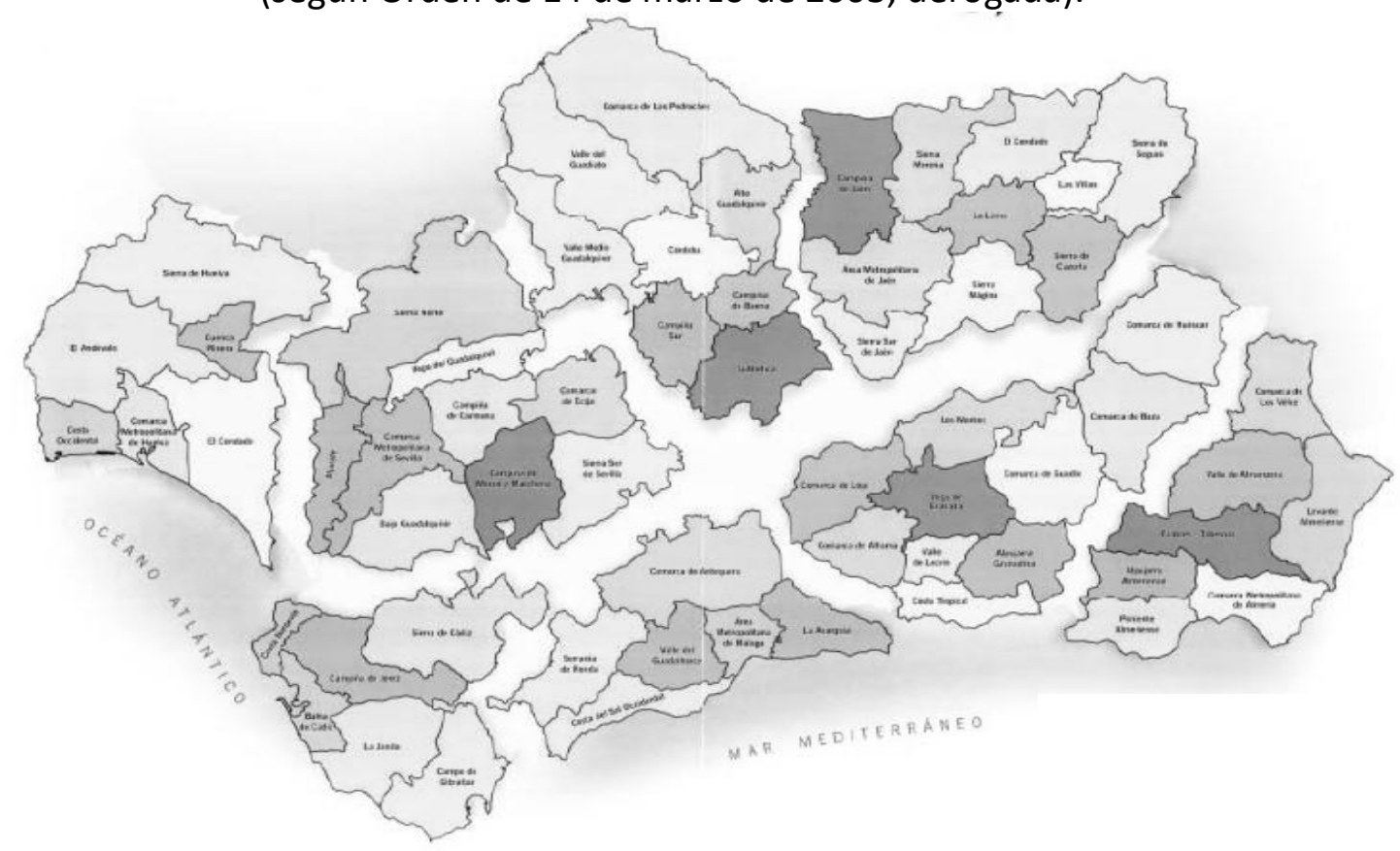

Fuente: Orden de 14 de marzo de 2003, por la que se aprueba el mapa de comarcas de Andalucía a efectos de la planificación de la oferta turística y deportiva.

La Ley 13/2011, de 23 de diciembre, del Turismo de Andalucía establece en la Estrategia de Turismo Sostenible, dos instrumentos de gran potencial para la formación de redes turísticas:

1.La Iniciativa de Turismo Sostenible (ITS), conjunto de medidas dinamizadoras y participadas de fomento, dirigidas a espacios con un importante potencial turístico que cuentan con recursos patrimoniales naturales o culturales de interés.

ISSN: 0212-8594 ISSN-e: 2340-2776. № DOI: http://dx.doi.org/10.12795/rea.2013.i30.05

REA 30 (2013):102-126

http://www.publius.us.es/estudios_andaluces 
2. La Iniciativa de Ciudades Turísticas (ICT), conjunto de medidas dinamizadoras y participadas de fomento, dirigidas a crear espacios turísticos en redes de ciudades medias y, entre ellas, las declaradas por la Unesco como Patrimonio de la Humanidad, y a establecer o consolidar rutas culturales o itinerarios turísticos en los que, mediante una gestión integrada de los recursos patrimoniales en un marco geográfico coherente, sea posible ofertar productos de turismo de naturaleza, cultural o monumental de gran atractivo. La Orden de 18 de mayo de 2011, que desarrolla la Estrategia de Turismo Sostenible y regula el procedimiento de selección de los Programas de Turismo Sostenible: aboga por estrategias de alcance comarcal, en determinadas zonas, que permitan ubicar los productos singulares en los mercados turísticos y las redes colaborativas. En este sentido, establece criterios selectivos relativos a la Identidad geográfica (territorio homogéneo desde el punto de vista turístico y de imagen comarcal); o identificación del territorio con el producto turístico; la colaboración público-privada en el producto (clubes de producto), las actuaciones de estructura que integren el desarrollo de nuevos espacios turísticos o mejora de los ya existentes a través del impulso de la actividad turística en uno o varios de los municipios incluidos en el ámbito de intervención del Programa de Turismo Sostenible, y el esfuerzo asociativo de los promotores que integren iniciativa público y privada.

Desde la puesta en marcha de la Estrategia de Turismo Sostenible, se han puesto en marcha 31 iniciativas en las ocho provincias andaluzas (Consejería de Turismo, Comercio y Deporte, 2012). Las zonas costeras donde se desarrollan son el Poniente almeriense, la Costa Occidental de Huelva, la Costa del Sol-Axarquía en Málaga, la Costa Tropical de Granada, y el Litoral de la Janda y la Bahía de Cádiz. En zonas de interior destacan los programas de la Subbética Cordobesa, Los Pedroches y Medio Guadalquivir en Córdoba; la Campiña de Jerez, Los Alcornocales, Sierra de Cádiz en la provincia gaditana; Comarca de Baza, Poniente y el Altiplano de Granada; Úbeda y Baeza, Cuenca Minera, Sierra Mágina y Sierra Sur en Jaén; Sierra de las Nieves en Málaga; y la Gran Vega y Sierra Sur en Sevilla. A estas actuaciones se suman otras de ámbito supraprovincial, como los de Doñana, Vía Verde de la Sierra, Villas Termales, Guadalquivir a Caballo, Conjuntos Históricos de Andalucía, Sierra Morena, Tempranillo, Faja Pirítica del Suroeste Peninsular y Ciudades Medias del Centro de Andalucía.

La colaboración entre redes complementarias y próximas, como la red de Paradores de Turismo, la Red de Espacios Naturales Protegidos de Andalucía y la Red Patrimonia, esta última compuesta por municipios de menos de 5.000 habitantes de alto valor ambiental, y arquitectura y urbanismo tradicional, ejercen un efecto sinérgico positivo para el conjunto de destinos y productos turísticos. Otro ejemplo; la aparición de un área de influencia en torno al núcleo turístico principal (hinterland turístico) que conecte con zonas del traspaís. Costa del Sol, Sierra de Ronda y Sierras de Tejeda y Almijara constituyen por estas fórmulas ofertas muy complementarias y cercanas.

ISSN: 0212-8594 ISSN-e: 2340-2776. № DOI: http://dx.doi.org/10.12795/rea.2013.i30.05

REA 30 (2013):102-126

http://www.publius.us.es/estudios_andaluces 
Fórmulas cooperativas y redes en turismo. Aplicación y potencial en Andalucía.

Tabla 2. Programas de Turismo Sostenible seleccionados en 2012.

\begin{tabular}{|c|c|c|}
\hline $\begin{array}{l}\text { No } \\
\text { puntua } \\
\text { ción }\end{array}$ & Programa de Turismo Sostenible & Entidad que lo presenta \\
\hline 1 & ITS Valle de Lecrín, Caminos de Agua & $\begin{array}{l}\text { Asociación de Turismo Sostenible Turisvalle- } \\
\text { Lecrin }\end{array}$ \\
\hline 2 & ITS Sierra Morena & ADIT Morena \\
\hline 3 & la ITS Via Salaria & Asociación Andaluza Turismo y Sal \\
\hline 4 & $\begin{array}{l}\text { ITS Rutas Paisajísticas Urbanas Sierra de } \\
\text { Segura }\end{array}$ & $\begin{array}{l}\text { Asociación para el Desarrollo Rural de la } \\
\text { Sierra de Segura }\end{array}$ \\
\hline 5 & ITS Valle del Alto Guadiato & $\begin{array}{l}\text { Grupo de Desarrollo Rural Valle del Alto } \\
\text { Guadiato }\end{array}$ \\
\hline 6 & ITS Vuelo Libre de Andalucía & $\begin{array}{l}\text { Asociación Vuelo Libre Andalucía del Medio } \\
\text { Rural }\end{array}$ \\
\hline 7 & $\begin{array}{l}\text { Iniciativa de Ciudades Turísticas (ICT) Cluster } \\
\text { de Innovación Turística Tierras de José María } \\
\text { El Tempranillo }\end{array}$ & $\begin{array}{l}\text { Centro de Dinamización Rural Jose Mạ “El } \\
\text { Tempranillo" }\end{array}$ \\
\hline 8 & ITS Guadajoz Parque Cultura & $\begin{array}{l}\text { Asociación para el Desarrollo del Guadajoz y } \\
\text { Campiña Este de Córdoba }\end{array}$ \\
\hline 9 & ITS Valle de Almanzora & $\begin{array}{l}\text { Asociación de Turismo Sostenible Valle del } \\
\text { Almanzora }\end{array}$ \\
\hline 10 & ITS Parque Minero Linares-Carboneros & $\begin{array}{l}\text { Asociación para el Desarrollo Turístico } \\
\text { Sostenible del Parque Minero Linares- } \\
\text { Carboneros }\end{array}$ \\
\hline 11 & ITS Levante Almeriense & $\begin{array}{l}\text { Asociación de promotores turísticos del } \\
\text { levante almeriense }\end{array}$ \\
\hline 12 & $\begin{array}{l}\text { Poniente Granadino "Productos y } \\
\text { Comercialización" }\end{array}$ & $\begin{array}{l}\text { Asociación para el Desarrollo Sostenible del } \\
\text { Poniente Granadino }\end{array}$ \\
\hline 13 & ITS Pablo de Olavide & Fundación de Municipios Pablo de Olavide \\
\hline 14 & $\begin{array}{l}\text { ITS Comarca de Huescar "Descubre tus } \\
\text { orígenes y déjate llevar" }\end{array}$ & $\begin{array}{l}\text { Asociación para la Promoción y Desarrollo } \\
\text { Socioeconómico y Turístico de las } \\
\text { Altiplanicies Granadinas APROTUR }\end{array}$ \\
\hline 15 & ITS Valle del Guadalhorce & Asociación Turismo Guadalhorce Ecológico \\
\hline 16 & ITS Gran Vega "Caudal del Guadalquivir" & Asociación Comarcal Gran Vega de Sevilla \\
\hline
\end{tabular}

Fuente: Elaboración a partir de Orden de 22 de marzo de 2012 de la Consejería de Turismo, Comercio y Deporte, sobre selección de programas de turismo sostenible. ITS: Iniciativa de Turismo Sostenible. ICT: Iniciativa de Ciudades Turísticas.

\subsubsection{REDES DE CIUDADES TURÍSTICAS ANDALUZAS.}

Aparte de las redes comentadas anteriormente en el POTA, sobresale la concurrencia de redes en el caso particular de la ciudad de Córdoba, que pertenece a las redes turísticas de Ciudades Patrimonio de la Humanidad, red de Ciudades AVE, Red de Ciudades Catedralicias, Red de Ciudades Turísticas Europeas, Red de Juderías, Red de Ciudades Río Guadalquivir, Red de Juderías de España, entre otras.

ISSN: 0212-8594 ISSN-e: 2340-2776. № DOI: http://dx.doi.org/10.12795/rea.2013.i30.05

REA 30 (2013):102-126

http://www.publius.us.es/estudios_andaluces 
El Plan General de Turismo Sostenible de Andalucía 2008-2011 recoge el proyecto de Guadalquivir Turístico, que trata de conectar nodos turísticos estratégicos a lo largo de la cuenca de este importante rio. Se trata de un ejemplo de producto y plan turístico desarrollado sobre una región natural de carácter hidrológico. Sin embargo, la red de embalses de Andalucía constituye una red de espacios y productos turísticos con un gran potencial de desarrollo, conectable además con la iniciativa de desarrollo en Extremadura de productos turísticos para el denominado turismo de embalses.

El Sistema Integral de Calidad Turística en Destino (SICTED) es un distintivo de calidad turístico, en el que participa un Ente Gestor y existe un sistema de requisitos a cumplir. Los destinos SICTED en Andalucía son Alcalá la Real, Antequera, Carmona,

Córdoba, Málaga, Mancomunidad de Islantilla (Lepe-Isla Cristina), Nerja, la Red Patrimonia y Sevilla. Aunque el mayor peso de la intervención en materia turística realizada en las ciudades durante los últimos años ha recaído sobre la administración local, las intervenciones buscan cada vez más el consenso de los representantes del tejido empresarial de la localidad, a partir del convencimiento de que el cambio en el modelo de intervención turística en destino pasa también por la modificación de la "cultura turística» de los empresarios locales-planteamientos que subyacen a la puesta en marcha de los Planes de Calidad en Destino (García, M.,2007).

La red de grandes ciudades turísticas patrimoniales y alta calidad de vida, como Sevilla, Granada, Córdoba, Málaga, núcleos y ciudades medias cercanas con buenas condiciones de accesibilidad, clima, cultura y elevada calidad ambiental, tienen un importante potencial para conformar redes de cooperación turístico-económicas, más allá del convencional turismo de congresos o negocios. La oportunidad: saber aprovechar el atractivo turístico de estos destinos para implantar infraestructuras, productos turísticos y servicios capaces de formar, retener y captar turistas cualificados, que combinen temporadas de ocio, aprendizaje y estancias de trabajo en grandes centros tecnológicos y de investigación, y en parques tecnológicos (Fernández, F.M., 2012).

\subsubsection{REDES Y CLUSTERS TURÍSTICOS EN ANDALUCÍA.}

Las aglomeraciones productivas o cluster son una concentración geográfica de empresas, proveedores de insumos y servicios especializados, e instituciones conexas, todos los cuales trabajan en forma coordinada, en estrecha interacción, de lo que derivan sinergias y externalidades positivas". (Porter, 1998). Los conceptos de cluster y red cooperativa están íntimamente relacionados, si bien el concepto de red no exige la concentración geográfica o proximidad espacial de sus empresas y entidades. En Andalucía el cluster turístico presenta grandes dimensiones, ocupa el segundo lugar

ISSN: 0212-8594 ISSN-e: 2340-2776. № DOI: http://dx.doi.org/10.12795/rea.2013.i30.05

REA 30 (2013):102-126

http://www.publius.us.es/estudios_andaluces 
entre los clusters de turismo del sur europeo, atendiendo al número de empleos que proporciona (figura 4).

Se obtiene una correlación estadística positiva, tal como se aprecia en la figura 5, entre el Monitor de competitividad turística relativa de las comunidades autónomas españolas (Monitur) y el número de clusters identificados por el Observatorio Europeo de Cluster. Esta asociación estadística $(r=0,62)$ plantea los posibles efectos que implica para la competitividad turística disponer de un conjunto diversificado de clusters en los destinos.

Figura 4. Tamaño de clusters turísticos en el sur europeo según número de empleos.

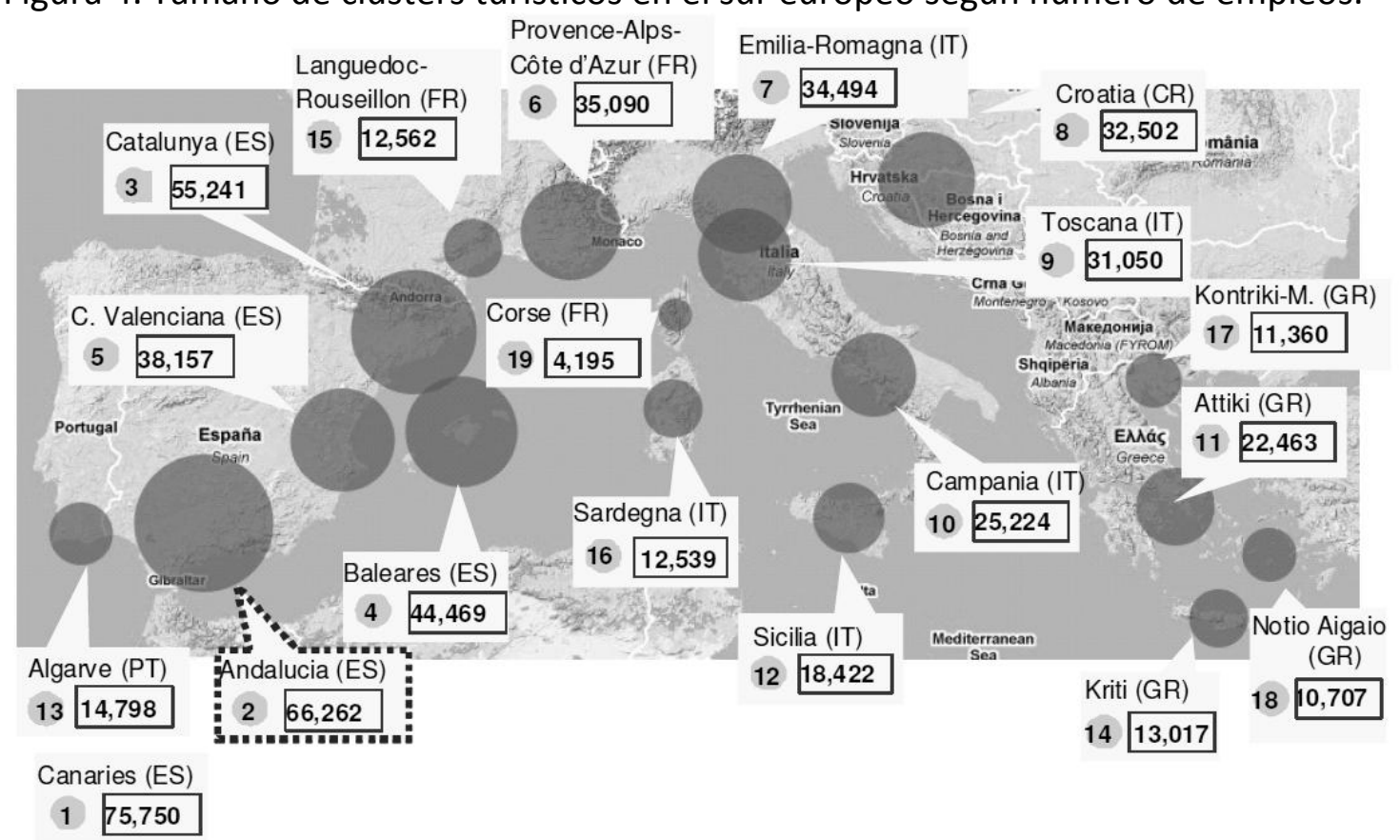

Fuente: Observatorio de Clusters de la Unión Europea

Los mecanismos y variables latentes que subyacen realmente en esta correlación se desconocen. Muy diversas explicaciones, interacciones y factores no controlados pueden entrar en juego, tales como la capacidad de innovación, el nivel de capital social y la dotación de recursos base disponibles en cada región, entre otros. Una explicación a confirmar sería que, cuando existe un clima socioeconómico y territorial que permite una amplia diversidad de clusters, intervienen ciertos mecanismos comunes que inciden positivamente en la competitividad turística. De forma que el cluster turístico "rentabiliza" de algún modo la diversidad de otros clusters presentes, la riqueza de recursos-base comunes, y muy importante, el clima favorable para la formación de redes cooperativas, aun cuando estas redes actúen de una forma no organizada ni aparente. Estos planteamientos inducen a explorar los beneficios de formular y aplicar políticas estatales, regionales y subregionales coherentes en materia

ISSN: 0212-8594 ISSN-e: 2340-2776. № DOI: http://dx.doi.org/10.12795/rea.2013.i30.05 
de clusters, fundamentadas en una estrategia conjunta de clusters en la que el turismo podría actuar como elemento articulador.

Se observa que Andalucía es la segunda comunidad con mayor diversidad de clusters en España, detrás de Cataluña, que ostenta el primer puesto. Esta diversidad de clusters constituye una fortaleza y una oportunidad para la adopción de una política integrada de clusters, en una comunidad, donde además, el sector turístico es de gran envergadura. Llama la atención que la monoespecialización turística -notoria en Baleares y Canarias- no garantiza una mayor competitividad turística según el indicador Monitur. Este dato conecta con la idea de que la diversificación es una de las estrategias de reestructuración turística más intensamente utilizadas (Perles, J. F., 2010), y con la recomendación del PNUMA (2006) de evitar economías dependientes en exceso del turismo. Es también sintomático que la región con mayor dotación de clusters (Cataluña) sea una de las comunidades con un mayor desarrollo de nuevos productos turísticos y de clubs de productos, como puede comprobarse en el portal turístico de esta comunidad.

La capacidad de Andalucía para ensayar esta política integrada de clusters es apreciable según la diversidad de clusters, y los indicadores de cooperación y de dotaciones para el turismo de negocios que se muestran en la tabla 3. Además, Andalucía cuenta con una alta conectividad de transportes, y una oferta de servicios y equipamientos adecuados para el turismo empresarial. Condiciones éstas, que en conjunción con una red de ciudades patrimoniales y espacios de alta calidad ambiental, propiciarían la formación de redes de cooperación turístico-económicas. El resultado final de conformar esta política integrada de clusters sería el establecimiento de redes con vínculos colaborativos permanentes entre clusters sectoriales de las regiones emisoras y receptoras de turismo, y de éstos con el cluster turístico. El diseño de estas redes y nuevos productos turísticos se llevaría a cabo atendiendo a los clusters claves presentes en cada destino, concertando políticas de ciencia, innovación y turismo con universidades, centros tecnológicos, formativos y asociaciones empresariales y turísticas. Un ejemplo pionero de colaboración entre clusters en esta línea es el impulsado en el Plan director para el desarrollo turístico-comercial en Andalucía, centrado en desarrollar rutas y productos turísticos especificos en ejes estratégicos entre ciudades turísticas y comerciales.

El turismo industrial podrá ser certificado con la $Q$ de Calidad Turística, a raíz de la publicación de la norma UNE 302001, aplicables a todos los servicios de turismo industrial, visitas y oferta complementaria, ya se trate de industria viva, de patrimonio industrial o de una combinación de ambas, incluyendo las infraestructuras, espacios y equipamientos vinculados a estos servicios así como su gestión interna (Hosteltur, 2012). Esta nueva certificación de calidad señala la importancia creciente del turismo industrial, y deja entrever el despliegue futuro del turismo empresarial, en sintonía con la propuesta de turismo de clusters que se formula en este artículo.

ISSN: 0212-8594 ISSN-e: 2340-2776. № DOI: http://dx.doi.org/10.12795/rea.2013.i30.05

REA 30 (2013):102-126

http://www.publius.us.es/estudios_andaluces 
Figura 5. Correlación entre el número de clusters y la competitividad turística medida por Monitur.

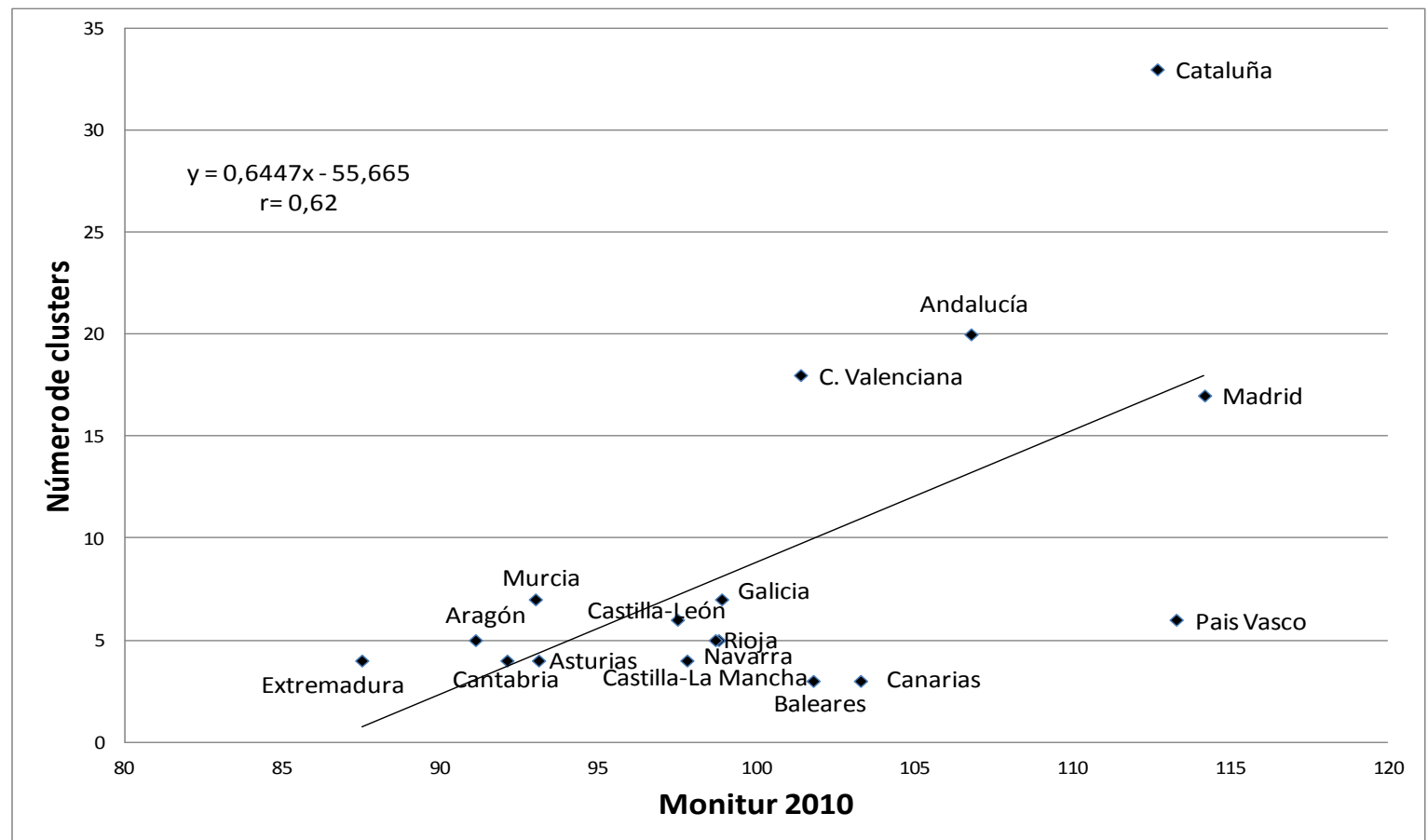

Fuente: Elaboración propia a partir de datos de Monitur 2010 y Observatorio Europeo de Cluster (2011). Correlación significativa al nivel 0,01 $(p=0,008)$.

Tabla 3. Indicadores de cooperación turística y aptitud para el turismo empresarial de Andalucía.

\begin{tabular}{|l|l|l|l|l|l|l|l|l|}
\hline & $\begin{array}{l}\text { Número } \\
\text { de } \\
\text { clusters }\end{array}$ & $\begin{array}{l}\text { Clubs de } \\
\text { producto } \\
\text { impulsados } \\
\text { por la CCAA }\end{array}$ & $\begin{array}{l}\text { Clubs de } \\
\text { producto } \\
\text { en } \\
\text { cooperaci } \\
\text { ón con } \\
\text { Turespaña }\end{array}$ & $\begin{array}{l}\text { Coordi- } \\
\text { nación } \\
\text { intercon } \\
\text { Sejerías }\end{array}$ & $\begin{array}{l}\text { Coopera- } \\
\text { ción con } \\
\text { sector } \\
\text { privado }\end{array}$ & $\begin{array}{l}\text { Plazas de } \\
\text { turismo } \\
\text { de } \\
\text { reuniones }\end{array}$ & $\begin{array}{l}\text { Hoyos de } \\
\text { clubs de } \\
\text { golf }\end{array}$ & $\begin{array}{l}\text { Visitas a } \\
\text { bodegas } \\
\text { de rutas } \\
\text { del vino }\end{array}$ \\
\hline Andalucía & 20 & 1 & 17 & 9 & 8 & 180.919 & 1.800 & 486.856 \\
\hline $\begin{array}{l}\text { Ranking } \\
\text { Andalucía }\end{array}$ & 2 & 9 & 1 & 2 & 5 & 2 & 1 & 1 \\
\hline Media & 8,9 & 5,3 & 8,3 & 3,4 & 5,4 & $59.131,7$ & 356,3 & $84.767,4$ \\
\hline Máximo & 33 & 25 & 17 & 13 & 12 & 239.186 & 1.800 & 486.856 \\
\hline Mínimo & 3 & 0 & 0 & 0 & 0 & 5.531 & 54 & 0 \\
\hline
\end{tabular}

Fuente: Elaboración propia a partir de datos de Monitur 2010 y Observatorio Europeo de Cluster (2011). Nota: los clubs de producto, la coordinación entre Consejerías y con el sector privado son indicadores de cooperación turística. Las plazas de turismo de reuniones, hoyos de clubs de golf y visitas a bodegas de rutas del vino son indicadores proxy de aptitud para el turismo empresarial.

ISSN: 0212-8594 ISSN-e: 2340-2776. № DOI: http://dx.doi.org/10.12795/rea.2013.i30.05

REA 30 (2013):102-126

http://www.publius.us.es/estudios_andaluces 


\subsubsection{CONSORCIOS Y MANCOMUNIDADES TURÍSTICAS.}

La formulación jurídica de redes dispone de dos instrumentos de gran tradición en el ámbito local, dotados de personalidad jurídica propia. Se trata de los consorcios y las mancomunidades de municipios. Entre los primeros sobresalen en el ámbito turístico los consorcios de la Costa del Sol Occidental, Consorcio de Turismo de Córdoba y Consorcio de Turismo de Sevilla, además de consorcios dirigidos la formación hostelera, a la gestión de equipamientos recreativos o culturales, o bien de recursos territoriales turísticos compartidos entre varios municipios, caso del Embalse de Iznájar. Entre los segundos, destacan por su naturaleza turística las mancomunidades de municipios de Islantilla y la mancomunidad de municipios Costa del Sol Occidental, representativas de espacios turísticos maduros y relativamente recientes, respectivamente.

\subsection{PROPUESTA DE UN MODELO DE TURISMO DE CLUSTERS.}

Se propone un modelo de turismo de clusters, que se representa en la figura 6 . Este modelo-red se basa en maximizar las relaciones entre el turismo y los clusters presentes en cada destino, entendidos éstos como recursos turísticos valorizables, directa o indirectamente. El modelo requiere diseñar y aplicar previamente una política integrada de clusters, e ir más allá del turismo de negocios convencional, y del propio turismo industrial y de visitas a empresas vivas. Se trata de una nueva modalidad turística cuyo como motivo central es el cluster en su conjunto (empresas, centros de investigación e instituciones conexas), lo que requiere adaptaciones para la implantación de nuevos productos, instalaciones y servicios turísticos, muy especializados y segmentados. Abarca variantes generalistas (dirigidas a turistas no especializados, esto es, gran público, como variante del turismo industrial a empresas en activo), y perfiles específicos dirigidos a empresas o sectores muy concretos, vinculadas a estancias mixtas de trabajo y ocio de distinta naturaleza, duración, y finalidad.

El modelo propuesto se ensaya en Andalucía (tabla 6), con el fin de facilitar la identificación de los principales clusters valorizables turisticamente, recursos turísticos vinculados, tipos de turismo potencial, y relación actual con el turismo. Aparte, se señalan clusters estratégicos de gran potencial turístico, perfil de nacionalidades de turistas y socios potenciales del cluster, así como integración existente con otros clusters.

En desarrollos ulteriores del modelo esta matriz se puede afinar mediante cruces con la matriz origen y destino de los turistas, con la matriz de balances comerciales del país origen y destino, e incluso con matrices de afinidad y atractivo cultural y comercial. Estos cruces pueden servir de ayuda en la priorización de clusters.

ISSN: 0212-8594 ISSN-e: 2340-2776. № DOI: http://dx.doi.org/10.12795/rea.2013.i30.05

REA 30 (2013):102-126

http://www.publius.us.es/estudios_andaluces 
Fórmulas cooperativas y redes en turismo. Aplicación y potencial en Andalucía.

Tabla 4. Caracterización de consorcios turísticos andaluces.

\begin{tabular}{|c|c|c|}
\hline Consorcio & Composición & Fines. Naturaleza \\
\hline $\begin{array}{l}\text { Consocio de Desarrollo y } \\
\text { Turismo Costa del Sol } \\
\text { Occidental }\end{array}$ & $\begin{array}{l}\text { Ministerio con competencias en Turismo, } \\
\text { Consejerías competentes en materia de } \\
\text { Economía y Hacienda, Vivienda y Ordenación } \\
\text { del Territorio, Turismo, Comercio y Deporte y } \\
\text { Medio Ambiente. Diputación Provincial de } \\
\text { Málaga, Ayuntamientos de Benalmádena, } \\
\text { Casares, Estepona, Fuengirola, Manilva, } \\
\text { Marbella, Mijas y Torremolinos. } \\
\text { Confederación de Empresarios de Andalucía. } \\
\text { Comisiones Obreras de Andalucía y la Unión } \\
\text { General de Trabajadores de Andalucía. }\end{array}$ & $\begin{array}{l}\text { Recualificación turística de la Costa } \\
\text { del Sol Occidental, de forma } \\
\text { coordinada y consensuada. } \\
\text { Gestión del Plan Qualífica de la } \\
\text { Costa del Sol Occidental. Carácter } \\
\text { supramunicipal. }\end{array}$ \\
\hline $\begin{array}{l}\text { Consorcio de Turismo de } \\
\text { Córdoba }\end{array}$ & $\begin{array}{l}\text { Ayuntamiento de Córdoba, Confederación de } \\
\text { Empresarios de Córdoba (CECO), Cámara } \\
\text { Oficial de Comercio e Industria de Córdoba, y } \\
\text { la asociación Córdoba Convention Bureau. }\end{array}$ & $\begin{array}{l}\text { Promoción y fomento del turismo } \\
\text { en la ciudad de Córdoba. Carácter } \\
\text { municipal. Participación en } \\
\text { diversas redes turísticas como red } \\
\text { de Ciudades AVE, the European } \\
\text { Cities Marketing-Avintur. }\end{array}$ \\
\hline $\begin{array}{l}\text { Consorcio de Turismo de } \\
\text { Sevilla }\end{array}$ & $\begin{array}{l}\text { Ayuntamiento de Sevilla, Diputación } \\
\text { Provincial de Sevilla, Consejería competente } \\
\text { en Turismo, Confederación de Empresarios } \\
\text { de Sevilla (CES) y Cámara de Comercio de } \\
\text { Sevilla. }\end{array}$ & $\begin{array}{l}\text { Promoción turística de la ciudad de } \\
\text { Sevilla y desarrollo de alternativas } \\
\text { al turismo tradicional. Ámbito: } \\
\text { Sevilla y su área metropolitana }\end{array}$ \\
\hline $\begin{array}{l}\text { Consorcio para el Desarrollo } \\
\text { del Entorno del Embalse de } \\
\text { Iznájar }\end{array}$ & $\begin{array}{l}\text { Ayuntamientos de Rute, Cuevas de San } \\
\text { Marcos, Algarinejo, Loja e Iznájar, Asociación } \\
\text { para el Desarrollo Rural de Andalucía }\end{array}$ & $\begin{array}{l}\text { Desarrollo armonizado del entorno } \\
\text { del embalse de Iznajar. Perfil } \\
\text { supramunicipal y pluriprovincial }\end{array}$ \\
\hline $\begin{array}{l}\text { Consorcio Escuela } \\
\text { Hostelería de Islantilla }\end{array}$ & Vinculada a la Mancomunidad Islantilla & $\begin{array}{l}\text { Formación en hostelería. } \\
\text { Supramunicipal }\end{array}$ \\
\hline $\begin{array}{l}\text { Consorcios Escuelas de } \\
\text { Hostelería de Málaga y } \\
\text { Benalmádena }\end{array}$ & Ayuntamientos de Málaga y Benalmádena & $\begin{array}{l}\text { Formación en hostelería. } \\
\text { Supramunicipal }\end{array}$ \\
\hline $\begin{array}{l}\text { Escuela de Hostelería y } \\
\text { Turismo La Laguna }\end{array}$ & Junta de Andalucía y Ayuntamiento de Baeza & Formación en hostelería y turismo \\
\hline $\begin{array}{llr}\text { Consorcio } & \text { Estación } \\
\text { Recreativa } & \text { Puerto de La } \\
\text { Ragua } & \end{array}$ & $\begin{array}{l}\text { Diputaciones de Almería y Granada, Aytos. } \\
\text { de Albuñan, Alcolea, Aldeire, Alquife, } \\
\text { Bayárcal, Cogollos de Guadix, Dólar, Ferreira, } \\
\text { Fondón, Huenéja, Jerez del Marquesado, La } \\
\text { Calahorra, Lanteira, Laujar de Andarax, } \\
\text { Paterna del Rio, Válor y Nevada }\end{array}$ & $\begin{array}{l}\text { Planeamiento y construcción de } \\
\text { espacio recreativo en el Puerto de } \\
\text { la Ragua. Turismo de nieve. } \\
\text { Supramunicipal y pluriprovincial. }\end{array}$ \\
\hline $\begin{array}{l}\text { Consorcio Parque de las } \\
\text { Ciencias }\end{array}$ & $\begin{array}{l}\text { Ayto. Granada, Universidad de Granada, } \\
\text { CSIC, Junta de Andalucía, Diputación de } \\
\text { Granada, Caja Granada, Caja Rural }\end{array}$ & $\begin{array}{l}\text { Gestión del Parque de las Ciencias } \\
\text { de Granada. }\end{array}$ \\
\hline $\begin{array}{l}\text { Consorcio Teatro de la } \\
\text { Maestranza }\end{array}$ & $\begin{array}{l}\text { Ministerio y Consejería competentes en } \\
\text { Cultura, Diputación de Sevilla, Ayuntamiento } \\
\text { de Sevilla }\end{array}$ & $\begin{array}{l}\text { Gestión y explotación del Teatro } \\
\text { de la Maestranza, salas de } \\
\text { Exposiciones de Sevilla }\end{array}$ \\
\hline
\end{tabular}

Fuente: Elaboración propia a partir de de datos de Consejería de Gobernación (2011). 
Fórmulas cooperativas y redes en turismo. Aplicación y potencial en Andalucía.

Tabla 5. Mancomunidades de municipios. Ejemplos de potencial de articulación.

\begin{tabular}{|c|c|c|}
\hline Mancomunidad de municipios & $\begin{array}{l}\text { Especialización. } \\
\text { Caracterización }\end{array}$ & $\begin{array}{l}\text { Potencial con otros clusters } 0 \\
\text { nodos }\end{array}$ \\
\hline Comarca del Mármol “Blanco Macael” & Mármol & $\begin{array}{l}\text { Conexión cluster turístico } \\
\text { almeriense-cluster del Mármol. }\end{array}$ \\
\hline Comarca de la Janda & Turismo, energía eólica & $\begin{array}{l}\text { Conexión cluster turístico-cluster } \\
\text { energia eólica }\end{array}$ \\
\hline Sierra de Cádiz & $\begin{array}{l}\text { Turismo de espacios } \\
\text { protegidos }\end{array}$ & $\begin{array}{lc}\text { Articulación con Reserva } \\
\text { Biosfera } \\
\text { Marruecos-España. Corcho. }\end{array}$ \\
\hline Alpujarra Granadina & $\begin{array}{lll}\text { Turismo de } & \text { espacios } \\
\text { protegidos } & & \end{array}$ & $\begin{array}{l}\text { Conexión con Red Alpujarra } \\
\text { Almeriense. Integración con } \\
\text { Costa Tropical y con Marruecos }\end{array}$ \\
\hline Costa Tropical de Granada & $\begin{array}{l}\text { Turismo litoral y agricultura } \\
\text { de productos tropicales }\end{array}$ & $\begin{array}{l}\text { Mayor integración con Alpujarra } \\
\text { Granadina. Agricultura sub- } \\
\text { tropical. Caña de azúcar-ron }\end{array}$ \\
\hline Mancomunidad del Bajo Guadalquivir & $\begin{array}{l}\text { Turismo diversificado con eje } \\
\text { Guadalquivir } \\
\text { cultural). }\end{array}$ & $\begin{array}{l}\text { Guadalquivir turístico. Sevilla-Sa } \\
\text { de Cádiz. Marca Sanlúcar de } \\
\text { Barrameda. Doñana. Agrocluster. }\end{array}$ \\
\hline Sierra Occidental de Huelva & $\begin{array}{l}\text { Turismo de espacio protegido } \\
\text { cercano a una capital. } \\
\text { Recurso cerdo ibérico }\end{array}$ & $\begin{array}{l}\text { Conexión con litoral onubense y } \\
\text { Alentejo. Mayor integración con } \\
\text { cluster del cerdo ibérico. } \\
\text { Conexión con Sa Norte de Sevilla }\end{array}$ \\
\hline Islantilla & $\begin{array}{l}\text { Turismo litoral. Municipios } \\
\text { Lepe-Isla Cristina }\end{array}$ & $\begin{array}{l}\text { Conexión cluster turismo-cluster } \\
\text { agricultura intensiva (fresa) y } \\
\text { pesca }\end{array}$ \\
\hline Cuenca minera (Riotinto) & Turismo industrial minero & $\begin{array}{l}\text { Mayor integración con Parque } \\
\text { Natural y cluster minero activo. }\end{array}$ \\
\hline $\begin{array}{l}\text { Mancomunidad intermunicipal Moguer-Palos } \\
\text { de la Frontera }\end{array}$ & $\begin{array}{l}\text { Turismo litoral próximo a } \\
\text { aglomeración industrial }\end{array}$ & $\begin{array}{l}\text { Integración cluster turismo con } \\
\text { cluster industrial. }\end{array}$ \\
\hline Sierra de las Nieves y su entorno & $\begin{array}{l}\text { Turismo de naturaleza } \\
\text { cercano al cluster Costa del } \\
\text { Sol }\end{array}$ & $\begin{array}{l}\text { Integración con Ronda y Costa } \\
\text { del Sol. }\end{array}$ \\
\hline Costa del Sol Occidental & Turismo litoral muy maduro & $\begin{array}{l}\text { Integración cluster turismo- } \\
\text { cluster tecnológico }\end{array}$ \\
\hline Costa del Sol Axarquia & Turismo litoral & $\begin{array}{l}\text { Complementación con Costa Sol } \\
\text { Occidental-Costa } \\
\text { Málaga capital }\end{array}$ \\
\hline Desarrollo y Fomento del Aljarafe & $\begin{array}{l}\text { Turismo de cercanía de } \\
\text { Sevilla }\end{array}$ & Integración Sevilla y Guadalquivir \\
\hline Comarca de Estepa & Mantecado & $\begin{array}{l}\text { Cluster turismo-cluster del } \\
\text { mantecado }\end{array}$ \\
\hline Comarca de Doñana & $\begin{array}{l}\text { Turismo litoral, religioso y de } \\
\text { naturaleza, marca Doñana, } \\
\text { espacio protegido } \\
\text { internacional }\end{array}$ & $\begin{array}{l}\text { Conexión turismo- acuicultura, } \\
\text { conexión Sevilla-litoral. Turismo } \\
\text { de negocios y congresos }\end{array}$ \\
\hline
\end{tabular}

Fuente: Elaboración propia.

ISSN: 0212-8594 ISSN-e: 2340-2776. № DOI: http://dx.doi.org/10.12795/rea.2013.i30.05

REA 30 (2013):102-126

http://www.publius.us.es/estudios_andaluces 
Figura 6. Modelo de turismo de clusters.

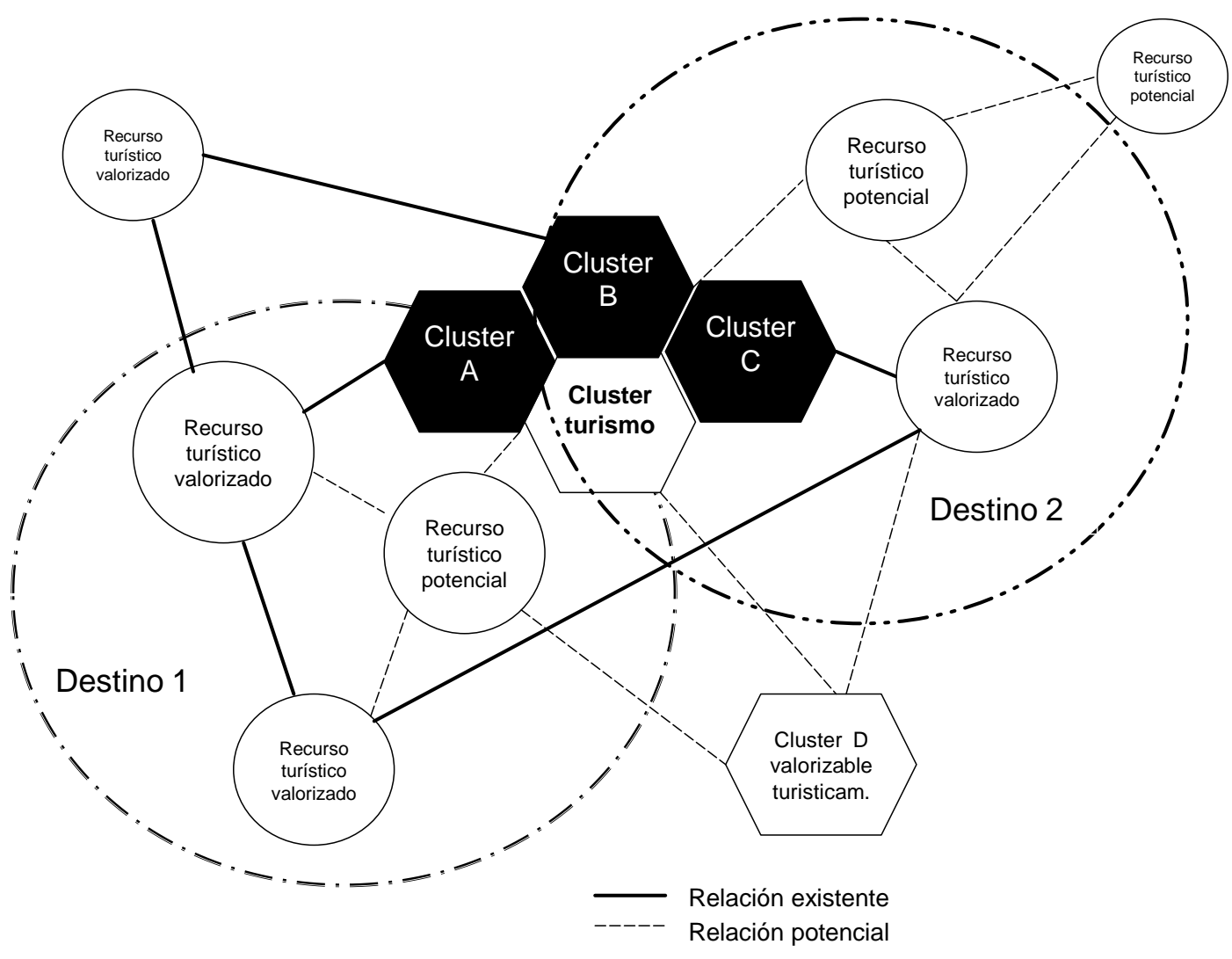

Fuente: Elaboración propia.

El turismo de clusters propuesto es afín -pero diferente- a otras modalidades existentes, caso del turismo industrial, el turismo de incentivos y el turismo científico. Requiere además instalaciones adaptadas a cada producto; e incluso adaptaciones y nuevas instalaciones en las empresas, bien para tener acceso a los medios técnicos y humanos necesarios para desempeñar sus fines en estancias mixtas de trabajo y turismo, bien adaptaciones para su visita, de carácter paisajístico-ambiental, de seguridad. La segmentación de productos de este tipo de turismo es muy amplia, y puede implicar la participación del turista en muy diversos grados, bien en régimen de una visita de poco más de una hora, una mañana o estancias de trabajo y formación de semanas o incluso meses. Admite combinaciones con turismo idiomático, de negocios y cultural.

ISSN: 0212-8594 ISSN-e: 2340-2776. № DOI: http://dx.doi.org/10.12795/rea.2013.i30.05 


\section{Francisco Fernández Latorre}

Fórmulas cooperativas y redes en turismo. Aplicación y potencial en Andalucía.

Tabla 6. Matriz del modelo de turismo de clusters en Andalucía.

\begin{tabular}{|c|c|c|c|c|}
\hline $\begin{array}{l}\text { Cluster } \\
\text { valorizable } \\
\text { turísticamente }\end{array}$ & $\begin{array}{l}\text { Recurso turístico/ } \\
\text { turismo potencial }\end{array}$ & $\begin{array}{l}\text { Relación actual } \\
\text { del cluster con el } \\
\text { turismo }\end{array}$ & $\begin{array}{lr}\text { Turistas y } & \text { socio } \\
\text { potencial } & \text { en } \\
\text { cluster estratégico }\end{array}$ & $\begin{array}{l}\text { Integración con otros clusters. } \\
\text { Observaciones }\end{array}$ \\
\hline Aeronáutico & $\begin{array}{l}\text { Parque Tecnológico } \\
\text { Aeroespacial de } \\
\text { Andalucía, (Aerópolis). } \\
\text { Campus Andalucía- } \\
\text { TECH/Turismo } \\
\text { tecnológico. }\end{array}$ & $\begin{array}{l}\text { Relación } \\
\text { inexistente, a } \\
\text { potenciar por su } \\
\text { carácter } \\
\text { estratégico }\end{array}$ & Francia y Alemania & $\begin{array}{l}\text { Colabora con clusters Cetemet/Plástico } \\
\text { (sede en Sevilla). Potencial por } \\
\text { proximidad a aeropuerto. Área de } \\
\text { excelencia del Campus Internacional } \\
\text { Andalucía-TECH, de la Universidad de } \\
\text { Sevilla y la Universidad de Málaga }\end{array}$ \\
\hline $\begin{array}{l}\text { Auxiliar } \\
\text { Agricultura }\end{array}$ & $\begin{array}{l}\text { Agroindustrias } \text { y } \\
\text { agricultura de alta } \\
\text { tecnología de Almería y } \\
\text { Huelva. }\end{array}$ & $\begin{array}{l}\text { Relación puntual } \\
\text { o inexistente, a } \\
\text { potenciar }\end{array}$ & $\begin{array}{l}\text { Francia, Italia, } \\
\text { Alemania }\end{array}$ & $\begin{array}{l}\text { Colaboración con otros clusters: } \\
\text { Citoliva/Acuicultura/Cetemet/Plástico. }\end{array}$ \\
\hline Biotecnología & $\begin{array}{l}\text { Empresas de base } \\
\text { biotecnológica. Turismo } \\
\text { de salud y bienestar. } \\
\text { Turismo tecnológico. }\end{array}$ & $\begin{array}{l}\text { Relación } \\
\text { inexistente, a } \\
\text { potenciar, por su } \\
\text { carácter } \\
\text { estratégico }\end{array}$ & $\begin{array}{l}\text { Gran Bretaña, } \\
\text { Alemania, Suiza, } \\
\text { Estados Unidos } \\
\text { (EEUU) }\end{array}$ & $\begin{array}{l}\text { Colaboración con clusters: } \\
\text { Salud/Agricultura-Citoliva/Citic } \\
\text { (Granada). Área de excelencia del } \\
\text { Campus Internacional Andalucía-TECH. } \\
\text { Cluster emergente. }\end{array}$ \\
\hline Cerámica & & Relación puntual & & $\begin{array}{lll}\text { Colaboración con } & \text { clusters: } \\
\text { Piedra/Plástico. Sede en Jaén. } & \\
\end{array}$ \\
\hline $\begin{array}{l}\text { Energías } \\
\text { Renovables }\end{array}$ & $\begin{array}{l}\text { Parques eólicos del } \\
\text { Estrecho de Gibraltar. } \\
\text { Instalaciones solares de } \\
\text { Sanlúcar la Mayor y } \\
\text { Almería }\end{array}$ & $\begin{array}{l}\text { Relación } \\
\text { inexistente, a } \\
\text { potenciar por su } \\
\text { carácter } \\
\text { estratégico }\end{array}$ & $\begin{array}{l}\text { Alemania, } \\
\text { Dinamarca, Francia, } \\
\text { EEUU }\end{array}$ & $\begin{array}{l}\text { Colaboración con cluster } \\
\text { Metalmecánico (eólica en Cádiz, solar } \\
\text { en Almería y Sevilla). Área de } \\
\text { excelencia del Campus Andalucía-TECH. } \\
\text { Cluster emergente. }\end{array}$ \\
\hline Madera y Mueble & & Relación puntual & & $\begin{array}{l}\text { Colaboración con cluster } \\
\text { Piedra/Plástico/TIC/Diseño Córdoba. }\end{array}$ \\
\hline Metalmecánico & & $\begin{array}{l}\text { Relación } \\
\text { inexistente }\end{array}$ & & $\begin{array}{l}\text { Colabora con Plástico/Ctaer/Energías } \\
\text { Renovables. Jaén. }\end{array}$ \\
\hline Oleícola & $\begin{array}{l}\text { Oleoturismo. } \\
\text { Oleoterapia. }\end{array}$ & $\begin{array}{l}\text { Relación } \\
\text { incipiente, a } \\
\text { potenciar por su } \\
\text { carácter } \\
\text { estratégico }\end{array}$ & $\begin{array}{l}\text { Francia, } \\
\text { EEUU }\end{array}$ & $\begin{array}{l}\text { Centro excelencia investigadora aceite } \\
\text { y salud, colabora con } \\
\text { Plásticos/Diseño/Cetemet. (Jaén). } \\
\text { Destacan Jaén, Córdoba y Sevilla. }\end{array}$ \\
\hline Piedra & & Relación puntual & & $\begin{array}{l}\text { Mármol de Macael en Almería. } \\
\text { Madera y Mueble/Cerámica/Plástico. }\end{array}$ \\
\hline Piel & & $\begin{array}{l}\text { Relación } \\
\text { existente, } \\
\text { potenciar }\end{array}$ & & $\begin{array}{l}\text { Turismo de compras y artesanía } \\
\text { concentrado en Ubrique (Cádiz). }\end{array}$ \\
\hline $\begin{array}{l}\text { Tecnologías de la } \\
\text { Información y la } \\
\text { Comunicación } \\
\text { (TIC) }\end{array}$ & $\begin{array}{l}\text { Centros y empresas } \\
\text { tecnológicas TIC. Centro } \\
\text { de innovación turístico } \\
\text { en colaboración con } \\
\text { Microsoft (Málaga). }\end{array}$ & $\begin{array}{l}\text { Relación } \\
\text { inexistente, a } \\
\text { potenciar por su } \\
\text { carácter } \\
\text { estratégico }\end{array}$ & $\begin{array}{l}\text { EEUU, Japón, } \\
\text { Alemania, } \\
\text { Finlandia, Gran } \\
\text { Bretaña }\end{array}$ & $\begin{array}{l}\text { Colabora con clusters } \\
\text { Piedra/Madera/Cerámica/Plástico -IC- } \\
\text { MED (Málaga). Área de excelencia del } \\
\text { Campus Internacional Andalucía-TECH. }\end{array}$ \\
\hline Cárnico & $\begin{array}{l}\text { Cerdo ibérico-dehesa. } \\
\text { Turismo cultural y } \\
\text { gastronómico. }\end{array}$ & $\begin{array}{l}\text { Relación puntual, } \\
\text { a potenciar }\end{array}$ & $\begin{array}{l}\text { China, EEUU, } \\
\text { Francia, Alemania }\end{array}$ & $\begin{array}{l}\text { Cluster emergente TEICA. Sierras de } \\
\text { Aracena, Norte de Sevilla y de Córdoba } \\
\text { (Pedroches). }\end{array}$ \\
\hline $\begin{array}{l}\text { Pesca } \\
\text { derivados }\end{array}$ & $\begin{array}{lr}\begin{array}{l}\text { Pescaturismo, } \\
\text { avistamiento } \\
\text { cetáceos, }\end{array} \\
\text { industrial. } & \text { turismo } \\
\end{array}$ & $\begin{array}{l}\text { Relación puntual } \\
\text { incipiente, a } \\
\text { potenciar }\end{array}$ & $\begin{array}{l}\text { Francia, } \\
\text { Gran } \\
\text { Japón }\end{array}$ & $\begin{array}{l}\text { Cluster GARUM. Conserveras y salazón } \\
\text { de pescado de Huelva y Cádiz. }\end{array}$ \\
\hline Acuicultura & $\begin{array}{lr}\text { Turismo } & \text { científico y } \\
\text { cultural. } & \text { Turismo } \\
\text { ornitológico } & \\
\end{array}$ & $\begin{array}{l}\text { Relación puntual, } \\
\text { a potenciar }\end{array}$ & & $\begin{array}{l}\text { CTAQUA en Cádiz. Vincular con cluster } \\
\text { pesca y derivados. }\end{array}$ \\
\hline $\begin{array}{l}\text { Industria química } \\
\text { y básica }\end{array}$ & $\begin{array}{lr}\text { Complejos } & \text { industriales } \\
\text { de Bahía de } & \text { Algeciras y } \\
\text { Huelva. } & \text { Turismo } \\
\text { industrial } & \end{array}$ & $\begin{array}{l}\text { Relación puntual, } \\
\text { a potenciar }\end{array}$ & $\begin{array}{l}\text { Alemania, Gran } \\
\text { Bretaña, Francia, } \\
\text { EEUU, China, Rusia }\end{array}$ & \\
\hline Joyería & & $\begin{array}{l}\text { Relación puntual, } \\
\text { a potenciar }\end{array}$ & & Cluster agrupado en Córdoba. \\
\hline
\end{tabular}

ISSN: 0212-8594 ISSN-e: 2340-2776. № DOI: http://dx.doi.org/10.12795/rea.2013.i30.05

REA 30 (2013):102-126

http://www.publius.us.es/estudios_andaluces 
Francisco Fernández Latorre

Fórmulas cooperativas y redes en turismo. Aplicación y potencial en Andalucía.

\begin{tabular}{|c|c|c|c|c|}
\hline Vitivinícola & $\begin{array}{l}\text { Cluster del vino de Jerez, } \\
\text { Huelva, } \quad \text { Montilla- } \\
\text { Moriles. } \\
\text { Enoterapia. }\end{array}$ & $\begin{array}{l}\text { Relación } \\
\text { existente, a } \\
\text { potenciar por su } \\
\text { gran potencial }\end{array}$ & $\begin{array}{l}\text { Francia, Italia, } \\
\text { Alemania, Gran } \\
\text { Bretaña, EEUU }\end{array}$ & $\begin{array}{l}\text { Es el cluster con mayor desarrollo } \\
\text { turístico actual. Existen iniciativas en } \\
\text { marcha como la Asociación Rutas del } \\
\text { Vino y brandy del marco de Jerez. }\end{array}$ \\
\hline Mantecado & & Relación puntual & & Microcluster de Estepa. \\
\hline $\begin{array}{l}\text { Construcción y } \\
\text { obra pública }\end{array}$ & & $\begin{array}{l}\text { Relación } \\
\text { existente, } \\
\text { potenciar }\end{array}$ & & $\begin{array}{l}\text { Centrar en aspectos de eficiencia } \\
\text { energética, domótica e Infraestructuras } \\
\text { singulares de transporte. }\end{array}$ \\
\hline Audiovisual & Turismo cinematográfico & $\begin{array}{l}\text { Relación } \\
\text { inexistente, } \\
\text { potenciar }\end{array}$ & EEUU; Japón & $\begin{array}{l}\text { Concentrado en Sevilla y Málaga. } \\
\text { Efecto sinérgico sobre marca Andalucía } \\
\text { y marca España. }\end{array}$ \\
\hline $\begin{array}{l}\text { Transporte } \quad \text { y } \\
\text { logística }\end{array}$ & & $\begin{array}{l}\text { Relación } \\
\text { inexistente, } \\
\text { potenciar }\end{array}$ & & $\begin{array}{l}\text { Servicios de transporte (AVE, Talgo, } \\
\text { compañías aéreas) y áreas logísticas } \\
\text { (Puerto de Algeciras). }\end{array}$ \\
\hline Minería & $\begin{array}{l}\text { Riotinto y otras áreas } \\
\text { mineras. } \quad \text { Turismo } \\
\text { industrial minero }\end{array}$ & $\begin{array}{l}\text { Relación } \\
\text { existente, } \\
\text { potenciar }\end{array}$ & & $\begin{array}{l}\text { El yacimiento de Cobre Las Cruces es } \\
\text { una gran explotación activa y potencial } \\
\text { recurso turístico. }\end{array}$ \\
\hline Caballo andaluz & & $\begin{array}{l}\text { Relación } \\
\text { existente, } \\
\text { potenciar }\end{array}$ & & $\begin{array}{l}\text { Proyecto Equitur. Turismo ecuestre en } \\
\text { el Guadalquivir. Icono andaluz. }\end{array}$ \\
\hline Flamenco & & $\begin{array}{l}\text { Relación } \\
\text { existente, } \\
\text { potenciar }\end{array}$ & & $\begin{array}{l}\text { Microcluster de gran importancia en el } \\
\text { imaginario turístico regional. }\end{array}$ \\
\hline $\begin{array}{l}\text { Ecoturismo } \\
\text { turismo } \\
\text { sostenible }\end{array}$ & $\begin{array}{l}\text { Centro de innovación } \\
\text { turística Andalucía Lab } \\
\text { (Marbella). Instalaciones } \\
\text { hoteleras modélicas. } \\
\text { Red de Espacios } \\
\text { Naturales Protegidos de } \\
\text { Andalucía. }\end{array}$ & $\begin{array}{l}\text { Relación } \\
\text { inexistente, a } \\
\text { potenciar por su } \\
\text { carácter } \\
\text { estratégico }\end{array}$ & $\begin{array}{l}\text { Alemania, Gran } \\
\text { Bretaña, Francia, } \\
\text { Suiza, países } \\
\text { escandinavos }\end{array}$ & $\begin{array}{l}\text { Instalaciones ejemplares de cadenas } \\
\text { hoteleras españolas con buenas } \\
\text { prácticas ambientales (ejemplo: hotel } \\
\text { Barceló La Bobadilla, que emplea los } \\
\text { residuos de los huesos de la aceituna } \\
\text { como fuente de energía renovable). } \\
\text { Área de excelencia del Campus } \\
\text { Internacional Andalucía-TECH. }\end{array}$ \\
\hline Medio ambiente & $\begin{array}{l}\text { Empresas avanzadas en } \\
\text { tecnologías del agua, } \\
\text { residuos, } \\
\text { medioambiental, } \\
\text { conservación, } \\
\text { agricultura y ganadería } \\
\text { ecológica }\end{array}$ & $\begin{array}{l}\text { Relación } \\
\text { inexistente, a } \\
\text { potenciar por su } \\
\text { carácter } \\
\text { estratégico }\end{array}$ & & $\begin{array}{l}\text { Andalucía es líder nacional en empleo } \\
\text { medioambiental junto a Cataluña. El } \\
\text { medio ambiente es un área de } \\
\text { excelencia del Campus Andalucía-TECH. } \\
\text { Cluster emergente. }\end{array}$ \\
\hline
\end{tabular}

Fuente: Elaboración propia. Datos de clusters: Asociación Española de Agencias de Desarrollo Regional

(2010) y CEA-Junta de Andalucía (2011). En negrita: clusters estratégicos de gran potencial turístico.

\section{CONCLUSIONES.}

El desarrollo temprano del cluster del turismo en Andalucía favoreció el desarrollo de redes ligadas al turismo, si bien el potencial de mejora es amplio aún. Los resultados muestran una correlación estadística positiva entre el Monitor de competitividad turística relativa de las comunidades autónomas españolas (Monitur) y el número de clusters identificados. La investigación sugiere que el turismo puede jugar una función conectora entre clusters, y que éstos pueden constituir en sí un recurso turístico. Se propone un modelo-red de turismo de clusters, basado en maximizar las relaciones entre el turismo y los clusters presentes en cada destino, entendidos como recursos turísticos valorizables, directa o indirectamente. El potencial de Andalucía en esta modalidad de turismo es alto, debido tanto a la diversidad e interés de los clusters existentes como a las buenas condiciones de partida para su desarrollo,

ISSN: 0212-8594 ISSN-e: 2340-2776. № DOI: http://dx.doi.org/10.12795/rea.2013.i30.05

REA 30 (2013):102-126

http://www.publius.us.es/estudios_andaluces 
complementariedad con otros recursos turísticos, y magnitud del cluster turístico. Son necesarios estudios adicionales para confirmar y profundizar en la función del turismo como multiplicador colaborativo entre clusters, catalizador de procesos de clusterización y marca territorial, así como en el diseño práctico de estrategias de turismo de clusters para el desarrollo regional.

\section{BIBLIOGRAFÍA}

Asociación Española de Agencias de Desarrollo Regional (2010). Clusters en el ámbito de las ADRs. Instituto de Fomento de la Región de Murcia.

Brunet, P., Almeida, F., Coll, M., Monteserín, O. (2005): “Los planes de excelencia y dinamización turística (PEDT), un instrumento de cooperación a favor del desarrollo turístico". Boletín de la Asociación de Geógrafos Españoles, №. 39, pp. 201-226.

CEA-Junta de Andalucía (2011: "Los clusters empresariales en Andalucía. Una oportunidad para crecer". CEA-Junta de Andalucía.

Consejería de Gobernación (2011): Guía de Entidades Locales de Andalucía. 2007-2011. Tomo II. Mancomunidades y consorcios locales de Andalucía. Consejería de Gobernación.

Consejería de Turismo, Comercio y Deporte (2010): Plan de Calidad Turística de Andalucía 2010-2012. Consejería de Turismo, Comercio y Deporte. http://www.juntadeandalucia.es/turismocomercioydeporte/export/sites/ctcd/archivo s/turismo/calidad-turistica/PCTA1012_doc_Detalle_2_03_11_v2.pdf

Consejería de Turismo, Comercio y Deporte (2012): "La Junta aprueba 16 nuevos Programas de Turismo Sostenible". Consejería de Turismo, Comercio y Deporte.

http://www.juntadeandalucia.es/turismocomercioydeporte/turismoycomercio/opencms/notic ias/noticia_1882.html

Contreras, G.A. y Jiménez, E. (2010): Plan de Acción para el Desarrollo Rural Sostenible vinculado al río Guadalquivir y sus principales afluentes. Instituto de Desarrollo Regional. Fundación Universitaria. Documento inédito. Sevilla, 15 páginas.

Dematteis, G. y Governa, F. (2005): "Territorio y territorialidad en el desarrollo local. La contribución del modelo SloT”. Boletín de la A.G.E. no 39, pp. 31-58.

Dollfus, O.,(1986): “Vous dites: geographie regionale?. Deux ou tres choses que je sais d'elle". L'Espace Géographique, XIV, pp. 257-258.

http://dx.doi.org/10.3406/spgeo.1986.4164

ISSN: 0212-8594 ISSN-e: 2340-2776. № DOI: http://dx.doi.org/10.12795/rea.2013.i30.05

REA 30 (2013):102-126

http://www.publius.us.es/estudios_andaluces 
Espejo Marin, C. (2003): “Anotaciones en torno al concepto de región”. Nimbus, no 1112, pp. 67-87.

Exceltur (2011): MONITUR 2010. Monitor de competitividad turística relativa de las comunidades autónomas españolas. Exceltur.

Fernández Latorre, F.M. (2012): Formación, investigación e innovación en turismo. Editorial Digital@tres. Disponible en:

http://dialnet.unirioja.es/servlet/libro?codigo=496941

Galiana Martín,L. y Barrado Timón, D. (2006): “Los centros de interés turístico nacional y el despegue del turismo de masas en España". Investigaciones Geográficas, no 39 pp. 73-93.

García Hernández, M. (2007): “Entidades de planificación y gestión turística a escala local. El caso de las ciudades patrimonio de la humanidad de España". Cuadernos de Turismo, no 20, pp. 79-102.

HOSTELTUR (2012): El turismo industrial entra en la $Q$ de calidad. http://www.hosteltur.com/184620_turismo-industrial-entra-q-calidad.html

Manero Miguel, F. (2012): “La cooperación intermunicipal como estrategia de ordenación y desarrollo territorial en espacios transfronterizos: la Agrupación Europea de Cooperación Territorial Duero-Douro". Boletín de la Asociación de Geógrafos Españoles N.o 58, pp.249-272.

Tresserras, J.J. Y Matamala, J.C. (2005): “El turismo cultural en España como fuente de empleo para los profesionales del patrimonio". PH Boletín del Instituto Andaluz del Patrimonio Histórico, no 54, pp. 73-83.

Perles Ribes, J. F. (2010): "Valorización de productos y reestructuración de destinos turísticos maduros: el papel de las agencias de desarrollo local". Gran Tour: Revista de Investigaciones Turísticas no 2 pp. 23-40.

PNUMA (2006): Por un turismo más sostenible. Guía para responsables políticos. PNUMA.

Porter, M. (1998): "Clusters and the new economics of competition", Harvard Business Review, noviembre-diciembre, pp. 77-87.

Vera, J.F. (coord.); López Palomeque, F.; Marchena, M. y Clavé, S. (1997): Análisis Territorial del Turismo. Editorial Ariel. Barcelona.

ISSN: 0212-8594 ISSN-e: 2340-2776. № DOI: http://dx.doi.org/10.12795/rea.2013.i30.05 